and has been developed to a stage in which, failing the latter contingency, it is likely to be widely accepted. Assuming it to be correct, man occupies to the parasite the position of what he terms an "optional host," in which parasitism is neither necessary for nor inimical to the continuance of the species.

Another case of such possible relationship may be mentioned. In 1889 , it was shown by Drs. Smith and Kilborne ${ }^{1}$ that the socalled "Red-water" or "Texas fever" of cattle is a disease of malarial type due to the presence in the red blood-corpuscles of bodies presenting a certain similarity to Laveran's parasite. In this disease the sole form of infection known is by the agency of cattle-ticks (Ixodidx), in which, notwithstanding their undoubted transmissive part, we believe the entozoon has hitherto not been detected in any stage.

Without attempting in any way to prescribe a line of research which Dr. Bruce is unlikely to overlook, it is impossible not to foreshadow the interest which will attach to an examination of the evolutions of the parasite in the body of the Tsetse, an examination which may end by showing that the insect, even if it possesses no specific virus in the older sense, may play an essential part in the economy of the hæmatozoon.

The symptoms, course, and pathology of Nagana are treated very fully by Dr. Bruce in a series of clinical cases, accompanied by charts indicating the variations of temperature, and the percentages of red blood-corpuscles and hæmatozoa. Suffice it here to say that the red blood-corpuscles may be reduced to onethird of their normal amount, and in one dog, at the point of death, bore to the parasites the proportion only of ten to one. $\mathrm{He}$ finds it invariably fatal in the horse, ass and dog-perhaps not necessarily so in cattle-in which it runs a much slower course. Two graphic and painful pictures are given of a donkey and a dog in the last stage of this distressing disease, and one is glad to learn that there is little suffering, and that the appetite rarely fails up to the last.

Of the new facts contained in this report, perhaps the most welcome is that Dr. Bruce finds that arsenic, so far as he has been able to try it, has a marked action on Nagana, causing disappearance of the hrematozoa, reduction in temperature, and mainteriance of the normal number of red blood-corpuscles. That it is a complete cure or prophylactic remains to be shown. The same result has been found in Surra, though the proportion of cases mentioned by Dr. Lingard as cured by treatment with arsenic is but small. This appears to be due partly to the extreme debility of many animals at the time of its first administration, and to the large and sometimes poisonous doses required. Its effects, nevertheless, are so remarkable as to give good ground for hoping that, when the limits of utility and safety of the drug, especially as a preventive, or in the early stages of disease, are determined, the trivial addition of a supply of arsenic to the traveller's outfit will free the African colonist of, perhaps, his greatest source of anxiety.

In Surra attempts have been made to treat the disease by inoculation or injection of filtered serum from affected animals. They have not proved successful, nor, while admitting the importance of the fact that the range of forms attacked by it and Nagana is limited, is there any $\dot{a}$ prior $i$ reason why they should succeed. The class of diseases here noticed, of which malaria may be taken as the type, is not caused by bacteria; and though it is known that the vitality of hrematozoa is affected by alterations in the medium in which they live, as by the administration of quinine or arsenic, the ordinary methods of research and antitoxic treatment employed in bacteriology do not appear to be applicable to them.

In view of a tendency in the reports, both of Dr. Bruce and Dr. Lingard, to dwell in detail upon the clinical features of the respective diseases, it cannot be too strongly urged that, when once the pathogenic nature of the hæmatozoon has been established, these inquiries, in order to progress to a fruitful issue, must be conducted on zoological lines. The mode of reproduction, distribution and general bionomics of the hrematozoon, and, in the event of its possessing more than an accidental connection with the Tsetse, the economy of that insect, these are the essential subjects of research: and little light will be thrown on them by any amount of laboriously-compiled clinical and pathological details.

It is to be desired that Surgeon-Major Bruce's further and more complete reports shall be republished in England, or at least made easily accessible to the many persons interested in African colonisation.

WALTER F. H. BLANDFORD.

${ }_{1}$ Ann. Rep. U.S. Sec. Agric., r889, pp. 88-91 : 189o, pp. 92, 93, and 103I 10 ; and following year.

NO. I 38 I, vOL. 53$]$

\section{THE ACTION OF LIGHT ON THE IRIS,} DEMONSTRATED BY A NEW PUPILOMETER.

BROWN-SÉQUARD observed that, in the iris of batrachians and fishes, separated from the rest of the eye, the pupil contracts at the approach of a candle, a fact which he attributed to the direct action of the light on the muscular tissues of the iris, the nervous elements having already lost, as he thought, at the times of his experiment, all irritability. We may also ask if the iris of the living eye responds to the direct action of light.

This problem cannot be approached directly, because of the mobility of the eye and the extreme variability of the pupil.

My new pupilometer, constructed by the well-known engineer, Mr. Ph. Pellin, consists of a series of three tubes of increasing diameter, commencing with the ocular tube; the first is provided with a screen perforated by a very small hole, and with an adjustable frame which may be removed or brought near in a manner to fix the eye at the required distance (I2.8 $\mathrm{mm}$.), of the anterior focus of the eye. The last tube is closed by a ground glass, to $\mathrm{cm}$. in diameter; on the surface of this glass appear black and white circles with numerical graduations. All the peripheric zones of the ground glass which are not perceived by the retina illuminate the iris. In this manner I am able to distinguish the effect produced upon the pupil by suppressing the illumination of a portion of the iris by means of opaque rings of blackened copper successively arranged upon the glass, the apertures of which are precisely equal to the apparent surfaces of the pupil, and then suddenly removed. For the retina nothing is changed by changing these rings, since the opening of each ring equals precisely the apparent surface of the luminous admission; for the iris, on the contrary, all is changed, since the opacity of the interposed rings prevents the luminous rays from reaching it.

The experiment made under these conditions proves that there is almost always a dilatation of the pupil when the iris is withdrawn from the light. The process may be described as follows. The subject is requested to indicate the largest concentric circle that he is able to distinguish on the luminous background, whereupon I place against the background an opaque ring, the opening of which equals precisely the said concentric circle; after a few moments I remove the ring, and then the subject generally remarks the coincidence of the apparent surface of his pupil with a concentric circle of much greater diameter. I have noticed but two exceptions to this rule where the result was a contraction instead of enlargement. The dilatation varies from $\frac{1}{8}$ to $\frac{1}{73}$ of I mmq. for I mmq. of iris withdrawn from the light, and such. dilatation has generally been observed to be greater for the dark than for the light iris.

The great majority of dark eyes which prevails in southern latitudes is perhaps a provision of nature to thus protect the eye from the effect of too abrupt changes of luminous irritation.

In any case the variations of dimensions of the iris are much less when it is the iris alone which is subjected to light than when the iris and the retina are influenced together. It may be shown, for instance, that if I mmq. of the centre of the retina be withdrawn from the light, the iris is capable of increasing in size from I to $16 \mathrm{mmq}$.

If, with the pupilometer of Robert Iloudin, we observe the pupil of one eye while the iris of the other is obscured, we remark on the said pupil a dilatation from half to quarter of a millimetre in diameter; this goes to prove that the action of light on the iris is due, in part at least, to a reflex of cerebral origin ; but, on the other hand, we do not yet possess sufficient knowledge of the anatomy of the iris to enable us to say whether these variations are due to the direct action of light on muscular elements (as supposed by Brown-Séquard) or to the action of nervous centres yet unknown belonging to the iris.

I have studied the influence of a coloured disc on the pupil, allowing the coloured light to strike the retina, in which cases I remarked that the more luminous the colours the less the dilatation of the pupil : yellow and green, for instance, cause a greater dilatation than red or blue. Again, I have remarked just the contrary. The same contradictions, which may be explained by the fatigue of the eye, are manifest when we examine the isolated action upon the iris of rings cut from the same block as the aforesaid coloured disc.

I have also endeavoured to find with the new pupilometer the 
relation existing between the pupillary contraction and the illumination of the retina.

The discovery of the direct action of light upon the iris leads to a number of curious deductions.

I. We are now able to explain the cause of the intense photophobia which characterises the iritis, and it is probable that the examination of the iris by the new pupilometer from the point of view of its proper excitability will be very useful in the diagnosis of diseases of the eye.

2. It shows that our photometric measurements must involve a systematic error, although slight. When the eye is directed towards the most luminous of two lights of different intensities the iris contracts, tending thus to equalise for the retina the two lights. It is in this movement of the iris perhaps that we should seek an explanation of the contradictions which we meet continually between the data of our photometric processes and the data furnished by sensitive plants employed in the measurement of light. We know, for instance, that a branch of vitia sativa placed between two lights equal for our eye and equidistant from each other tends invariably to incline towards one of them.

Chariegs Henry.

IMMUNISATION AGAINST SERPENTS'

IENOM, AND THE TREATMENT OF SNAKEBITE WITH ANTIVENENE. ${ }^{1}$

I.

FROM a remote period of antiquity, there has been enmity between the human race and serpents, and, in a literal sense, man has bruised the head of the serpent, and the serpent has bruised the heel of man. This long-continued feud has not yet resulted in victory for either side. Venomous serpents still annually destroy the lives of tens of thousands of human beings, and, in self-defence, tens of thousands of serpents are annually slain by man.

The progress of knowledge has greatly increased the means for protecting mankind against the death-producing effects of many diseases; and, although these means have been liberally employed in the contest against venomous serpents, none of them bas hitherto been found sufficient.

The reality of the contest is appreciated when we find pervading medical literature from its earliest beginnings-from the time of Pliny and Celsus--to the present time, disquisitions on the treatment of the bites of venomous serpents, and lengthy descriptions of the numerous remedies, organic and inorganic, that have been used for this purpose. Although extended experience and the application of the scientific methods of the present day, have resulted in showing that each of these remedies had been recommended on insufficient grounds, we may hesitate in pronouncing their recommendation to have been premature, in view of the impossibility of waiting, in the presence of imminent dangers, until accurate demonstration has been obtained by the usually tardy and laborious processes of science.

Let me pause here for a few minutes to indicate the practical importance of a scientific demonstration of the value of any remedy that is used in the treatment of snake-poisoning.

When a serpent inflicts a wound, I need scarcely say that it is not the wound, but the venom introduced into it which causes the symptoms of poisoning, and the death that may result. This venom is now known to be a complex mixture, containing several non-poisonous as well as poisonous substances. The latter are not ferments and have no power of reproducing themselves in the body, but they are substances that produce effects having a direct relationship to the quantity introduced into the body. This quantity in the case of each serpent varies with its size and bodily and mental condition; with the nature of the bitewhether both fangs or only one have been introduced, whether they have penetrated deeply or only scratched the surface; and with other circumstances related to the serpent, such as whether it had recently bitten an animal or not, and thus parted with a portion or retained the whole of the venom stored in the poison glands.

A bite may, therefore, result in very little danger, or it may be rapidly fatal ; but, in order to produce death, there must have been introduced into the tissues at least a certain quantity

${ }^{1}$ An address delivered at the Royal Institution of Creat Britain, on Friday, March 20, by Prof. Thomas R. Fraser, F.R.S. of venom, which is spoken of as the minimum-lethal quantity or dose. The minimum-lethal quantity for the animal bitten, again, is different for different species of animals, and different also for different individuals of the same species, the chief cause of difference between animals of the same species being the body weight of the individual, the quantity required to produce death being very exactly related to each pound or kilogramme of weight.

If even a minute fraction below the minimum-lethal has been introduced into the tissues by an effective bite, death will not follow, although serious and alarming symptoms will be produced of exactly the same kind as those which follow a bite which terminates fatally.

How then can we be assured, in any case of snake-bite in man, that a quantity of venom sufficient to produce death has been introduced? It is impossible to answer this question except by the result. If a quantity less than the minimum-lethal has been introduced, although the gravest symptoms may be produced, the patient will recover whatever remedies are administered, provided, obviously, that the remedies have not been so injudiciously selected or used that they themselves, and not the insufficient quantity of venom, produce a fatal termination. The recovery of a patient after the introduction of less than the smallest quantity of venom capable of producing death, has thus too often been attributed to the remedies that have been administered ; and consequently, as, indeed, is exemplified in the treatment of many diseases, a large number of substances have acquired an unjust reputation as antidotes. The list of antidotes has, accordingly, become a very large one; but when their pretensions have been subjected to sufficient tests, the verdict is that all of them are valueless to prevent death when even the smallest quantity of venom required to produce death has been received by an animal.

Without entering into details, I will content myself with re producing the opinion of Sir Joseph Fayrer, that, "after long and repeated observations in India, and subsequently in England, I am forced to the conclusion that all the remedies hitherto regarded as antidotes are absolutely without any specific effect on the condition produced by the poison."

But while medical practice and science, in each period of its development, has thus failed to protect man against this ancient enemy, legendary traditions, the tales of travellers and of residents among nations and tribes existing outside of the civilisation of the time, at least suggest that, by means apart from the use of remedies, some measure of success may actually have been obtained.

Many of these legends and statements are probably of great significance, and, in connection with facts derived from experiment, which to-night $I$ have to describe, they possess a deep interest.

We learn from these legends that from a remote period of time the belief has existed that a power may be acquired by man of freely handling venomous serpents, and even of successfully resisting the poisonous effects of their bites.

The Psylli of Africa, the Marsi of Italy, the Gouni of India, and other ancient tribes and sects, were stated to have been immune against serpents' bites, and this immunity has been explained on the supposition that serpents' blood was present in. the veins of the members of these tribes and sects.

In more modern times and, indeed, at the present day, the same belief is expressed in the writings of many travellers. In "A New and Accurate Description of the Coast of Guinea," by William Bosman, published in I705, an account is given of the great "reverence and respect" of the negroes for snakes, worshipped by them as gods; in connection with which the following statements are made. "But what is best of all is that these idolatrous snakes don't do the least mischief in the world to mankind; for if by chance in the dark one treads upon them, and they bite or sting him, it is not more prejudicial than the sting of millipedes. Wherefore the natives would fain persuade us that it is good to be bitten or stung by these snakes, upon the plea that one is thereby secured and protected from the sting of any poisonous snake" (p. 379).

At Southern Africa, the Rev. John Campbell, in I8r3, observed that it was "very common among the Hottentots to catch a serpent, squeeze out the poison from under his teeth, and drink it. They say it only makes them a little giddy, and imagine that it preserves them afterwards from receiving any injury from the sting of that reptile" (p. 4OI).

Drummond Hay, in his work on Western Barbary, pub.

NO. I 38 I, VOL. 53] 